\title{
The Relationship between Management Practices and Safety
}

\author{
Siew Lee Cheng', Florianna Lendai Michael ${ }^{2 *}$, Hana Hamidi ${ }^{3}$ and Siti Mariam Abdullah ${ }^{4}$ \\ ${ }^{1-4}$ Universiti Malaysia Sarawak, 94300 Kota Samarahan, Sarawak, Malaysia
}

\begin{abstract}
Work-related accidents is a controversial topic in Malaysia as evidenced by the increased number of occupational accidents throughout the years. The purpose of this research is to examine the relationship between management practices and safety performance in an organization. The four management practices investigated are (a) training, (b) management commitment, (c) communication and feedback, and (d) employee involvement. The most effective safety practice is also identified. The data was collected at a manufacturing company located in Shah Alam, Malaysia using closed-ended questionnaire. 95 respondents from the production line were involved in this study. The result found that training had a very weak relationship to the safety performance while the management commitment, as well as the communication and feedback, revealed to have a weak impact on safety performance. On the other hand, the analysis showed that employee involvement is the most effective safety practice to the safety performance, as it had a moderate impact on safety performance.
\end{abstract}

Keywords: Workplace health and safety; accidents; injuries; safety performance

Copyright: This is an open access article distributed under the terms of the Creative Commons Attribution-NonCommercialShareAlike 4.0 International (CC BY-NC-SA 4.0) license which permits unrestricted use, distribution, and reproduction in any medium, for non-commercial purposes, provided the original work is properly cited.

\section{INTRODUCTION}

Work-related accidents in the workplace as of now still remains a controversial topic in Malaysia over the past ten years. Ranging from human error to machinery failure, structural and process design failure, harm-

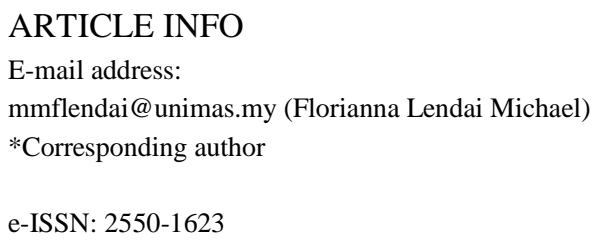

Manuscript received: 13 July 2018; Accepted: 27 Sept 2018. Date of publication: 30 Sept 2018 ful materials and substances, improper safety procedure in handling equipment and storage, unsafe working environment, which will lead to accidents and incur fatal, injury or illness (Makin \& Winder, 2008). A successful implementation of organization practices is able to facilitate safety culture and working environment, at the same time, reduce the injury and illness occurrence (Ali, Chew Abdullah \& Subramaniam, 2009).

Workplace hazards derived from management issues and internal risk management 
processes are likely to be overlooked (Makin \& Winder, 2008). In a research conducted by Chandraseker (2011), unsafe and unhealthy working environment led to work-related accidents and illnesses. Meanwhile, working environment is said to influence employees' attitude, behavior and satisfaction towards the company, which by default indicate that working environment indirectly affects an employee's performance.

According to Department of Occupational Safety and Health (DOSH) (2017) among ten sectors, manufacturing sector recorded the highest figure of accidents and numbers of victims. In the latest report of Occupational Accidents Statistics by Sector until October 2017 (DOSH, 2017), the manufacturing sector is reported to have the highest number of victims - 1691. While Occupational Disease and Poisoning by sector until 2016 mentioned in the report provided by the DOSH (2017) had revealed that manufacturing sector made up the most number of work-related diseases and poisoning cases, with a total of 3298 cases (85.4\%).

There were a lot of previous research studied on the workplace health and safety in construction, mining and oil and gas industry. However, only a small number of empirical studies were conducted in Malaysia, specifically the safety management of manufacturing sector Previous research for the past ten years in Malaysia focused on safety issues in construction industry (Ali et al., 2009; Zakaria et al., 2010; Said et al., 2012). Some research were conducted in different countries (Unnikrishnan, Iqbal, Singh, \& Nimkar, 2015) and can only be used as references. They are not fully applicable in
Malaysia. Differences of culture and socioeconomic background between western and eastern country contributed to the generalizability issue. The purpose of this research is to examine the relationship between management practices and safety performance within the organization.

\section{LITERATURE REVIEW}

\section{Workplace Health and Safety}

Every job virtually carried the potential risk of injuries or diseases (Leigh, 2011) and each accident, injury or disease developed from multi-linear interactions of the contributory factors and causes (Toft et. al., 2012). Workplace hazards are generated from three main components which included management decision, people, and physical workplace or environment which showed an interdependent relationship as each of the elements can interconnect and influence each other. According to Reason's Swiss Cheese Theory, the incident will happen when the combination of weaknesses which related to these three components in the defenses barriers, which contributes to damage and workplace accident (Reason, 2000).

Some researchers claimed that people who lack of awareness, inadequate knowledge, and attitude result in unsafe behaviour that causes injuries in the workplace (Eakin, 1992; DeRoo et al., 2000; Said el. al. 2012; Taufek, et. al., 2016). Reason (1997) contended that the occupational accidents were as a result of fail to recognize the potential hazards in the systems as there was lack of defenses used to prevent unwanted outcomes. On the other hand, Health and Safe- 
ty Executives (HSE, 2002) concluded that human behaviour is the leading factor of the accident occurrence.

\section{Safety Culture on Workplace Health and Safety}

Safety culture had become a greater interest in several industries as a means of reducing work-related accidents within the working places (Fernández-Muñiz, Montes-Peón \& Vázquez-Ordás, 2007). Also, safety climate increasingly important as an indicator of employees safety and health (Clarke, 2006) in various industries such as manufacturing (Probst \& Estrada, 2010), construction (Zakaria et al., 2010) and etc. Safety climate, also as known as safety culture is defined as the shared perceptions of workers on practices, procedures, and policies correspond to the importance of occupational safety in the organization (Sawhney, et al., 2011). Safety culture has earlier been shown to be related with work-related accidents and acts or behaviours (Brown et al., 2000; Watson et al., 2005) and recent research has successfully linked safety culture to safety practices (Guldenmund, 2010).

The study conducted by Christian, Bradley, Wallace, and Burke (2009) stated that the safety climate was positively affected safety performance behaviours and negatively influence outcomes. The study indicated that the factor of safety climate such as management commitment had increased the motivation of workers and the negative outcomes are accidents and injuries. Also, Schlesinger (2017) claimed that organizational culture and norms are part of the causes contributing to the accidents. People tend to follow the organization's norm where they follow the way they do thing over there, emphasizing on the production performance instead of safety concern (Schlesinger, 2017)

\section{Workplace Health and Safety in Manu- facturing Industries}

Economic expansion is the leading factor in occupational injuries and accidents (Kumar, et. al., 2012; Said, et. al., 2012). New workers who are not accustomed to the risks and procedures are employed in order to fulfil the workforce demand. Employer put excessive job demand on employees with diversified working requirements, thereby employees need more time to adapt the new skills, and the working hours extend, as well as increased in term of time pressure leading to the stress in the place of work (Christiansen, Bryan, Chandan, Harish, 2017). Hence, there were more injuries incidences reported within the workplace.

Mearns, Whitaker, and Flin (2003) claimed that safety management practices were associated with the safety performance and the rate of dangerous occurrence. Management plays the significant responsibility which to ensure a safe and healthy working environment (Ratnasingam, Ioras, \& Bennet, 2010) where the participation of management plays a very crucial roles in everything, especially in providing safety information to employees and conducting risk assessment and safety inspection to anticipate the hazards through job analysis to ensure safety performance.

\section{Training Impact}

The study of Schlesinger (2017) revealed that training is an opportunity to engage employees and mold their behaviour to the desired outcomes of the solution. An appro- 
priate training perceives as the best practice to reduce human factor that could lead to accidents in the working places. According to Said, Halim \& Said (2012), technical skill education and training program are the preventive actions to reduce the risk of getting harmed in the workplace. While, employers will have a ready workforce with necessary skills and knowledge to be hired to handle the safety machines, equipment, and devices.

A study of Smith-Crowe, Burke, and Landis (2003) found that safety knowledge has a moderate relationship with the safety performance. While the transfer of safety training program acts as the mediating factor between safety knowledge and safety performance. Hatala and Fleming (2007) stated that employees who involve in training are more likely to utilize the knowledge if they perceive it is relevant their work activities. However, Smith-Crowe, Burke, and Landis (2003) also claimed that the transfer of training would not effective without support from the organization.

\section{Management Commitment}

Management commitment to safety defined as "the extent to which management is perceived to place a high priority on safety, and communicate and act on safety issues effectively" (Neal and Griffin, 2014 as cited in Mashi, Subramaniam \& Johari, 2018). According to Barbera (2014) stated workers perceived the management should informed employees about the relevance of priority in term of safety and health and guiding employees the appropriate task behaviour that involved potential physical and health hazards and lead workers to develop consistent expected safety behaviour and outcomes and act accordingly, hence it could reduce the negative outcomes.

The initiatives of management commit and involve in term of safety policy enforcement and establishing safety rules and procedure would develop a sense of self-efficacy among workers to demonstrate safety behaviour (Mashi, Subramaniam, \& Johari, 2018) and could help to reduce the probability of employees get injured (Hon, Hinze \& PC Chan, 2014)/ Management is one of the determinants to ensure the success of workplace safety program. If the managers are committed and aware of the workers' safety, it will help to reduce the unsafety working condition (Choudhry, Fang \& Ahmed, 2008). Workers who work under supportive environment are more motivated to involve in safety activities as they feel satisfied because they have of sense of valued by the organization. It also stimulate the growth and learning among workers to work on safety practices such as to use the protective equipment (Nahrgang, Morgeson \& Hofmann, 2011).

\section{Communication and Feedback}

Hazards were likely occurred at the bottom level when the changes implemented but the managers failed to give adequate risk warnings through communicate revision on the work procedures or method after the changes (Makin \& Winder, 2008). Health and Safety Executives (HSE, 2002) concluded that human behaviour is the leading factor in approximately $80 \%$ of accident occurrence. The study showed that the likelihood of individual's behaviour will be repeated is influenced by the consequences of behaviour applied to the individual which are positive and negative reinforcement. 
Taufek, Zulkifle, and Kadir (2016) mentioned that it is crucial to communicate the procedures of improving the process of production with workers whenever an accident happens, instead of blaming and accusing the mistakes. However, the study of Health and Safety Executives (2002) also argued that the intention of the impact of consequences on individual's behaviour is determined by the person who performs the behaviour. It meant positive reinforcement does not take effect if an individual does not wish or is not willing to do so. Also, a study from Clarke (2006) reported that job communication was not the safety intervention as it failed to predict the safety outcomes such as accidents and unsafe behaviour.

\section{Employee Involvement in Safety Activi- ties}

Employees' involvement refers to the extent to which workers' aggressiveness in participating in the safety activities on daily basis (Ooshaksaraie \& Azadehdel, 2015). The research of Christian, Bradley, Wallace, and Burke (2009) showed that safety climate tended to have a significant relationship with the safety participation particularly employee involvement than safety compliance because workers were obliged or mandatory to obey the safety practices and procedures within the workplace.

However, the findings of Clarke (2006) demonstrated that the safety participation was weakly related to the accident incidences. The study of Ooshaksaraie and Azadehdel (2015) also found out that employee participation is the weakest component used to determine the safety performance within the workplace. They claimed that the low safety performance occurred without employees' attempt to engage in the safety issues, therefore it is considered as the poor indicator.

\section{Management Practices on Safety Perfor- mance}

Safety performance is the job behaviours and manners that facilitate the safety climate and well-being of company's stakeholders as well as the working environment (Burke et. al., 2002 as cited Smith-Crowe, Burke \& Landis, v2003). While Ooshaksaraie \& Azadehdel (2015) defined safety performance as the overall performance of the company's safety management system in their operation.

Levitt and Samelson (1986) claimed that safety performance is used to distinguish the problem areas occurred in the workplace (as cited in Dorji \& Hadikusumo, 2006). Measuring safety performance is the way to examine the effectiveness of the management practices especially the training intervention. The review of the safety performance acts as a feedback loop for the organization to improve and implement a better and effective plan and performance (Dorji \& Hadikusumo, 2006).

\section{METHODOLOGY}

The design of the study used is the casestudy research design. This study is to determine the effectiveness of management practices on workplace health and safety. The research was conducted by using the quantitative method which the closed-ended questions. The data collected were analysed by using Statistical Package for Social Science (SPSS) version 20.0. 
The research was conducted in a nongovernment food manufacturing company located in Shah Alam, Malaysia for the purpose of examining the effectiveness of management practices within the organization on safety performance. The sampling method chosen for the research is purposive sampling as the research focused on the employees only from the production line with the population of 400 employees. The sample size calculated based on the population of production employees using the table generated by Krejcie and Morgan (1970), thus the sample size required is 196 , however, only 95 questionnaires were returned due to time limitation. Pearson Correlation Test was used to analyse the strength of the relationship between independent variables (training, management commitment, communication and feedback and employee involvement) and the dependent variable (safety performance) as shown in Figure 1.

Figure 1: Independent and dependent variables

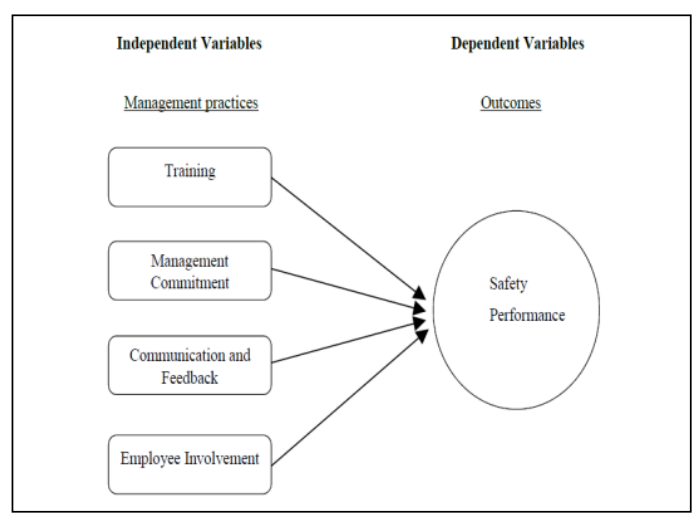

\section{RESULTS}

Hypothesis Ha 1 examines the relationship between training and safety performance, such as effectiveness of the training program or safety activities on the employee behaviour. The result showed a very weak relationship on safety performance. In other word, training activities have very less impact on safety outcomes and safety behaviour. While Hypothesis Ha 2 and Hypothesis Ha 3 predict management commitment as well as communication and feedback respectively. Both results showed weak correlations with safety performance. Hypothesis $\mathrm{Ha} 4$, on the other hand, used to predict employee involvement in safety performance such level of engagement on safety activities provided by the organization. It demonstrated a moderate correlation with safety performance. Employee involvement has the most significant impact among the four management practices. Table 1 presents a summary of the hypothesis testing results examining the effectiveness of management practices on safety performance.

Table 2 showed the result indicated that the multiple correlation was 0.555 and the $\mathrm{R}^{2}$ was 0.308 which indicated that 30.8 percent of the variance in safety performance is explained by employee involvement. A significant linear relationship between management practices and safety performance was obtained $[\mathrm{F}(4,90)=10.012, \mathrm{p}=$ $0.000]$. The coefficient of correlation indicated that only employee involvement $(\mathrm{t}=$ 4.498, $\mathrm{p}=0.000)$ was significantly related to safety performance. Training $(\mathrm{t}=0.103, \mathrm{p}$ $=0.919)$, management commitment $(\mathrm{t}=$ $0.725, \mathrm{p}=0.470)$, as well as communication and feedback $(\mathrm{t}=1.265, \mathrm{p}=0.209)$ were all not significantly related to safety performance.

\section{DISCUSSIONS}


Table 1: Summary of hypothesis testing.

\begin{tabular}{lccc}
\hline Hypothesis & p value & r value & Relationship strength \\
\hline $\begin{array}{l}\text { Ha 1: There is a significant relationship be- } \\
\text { tween safety training programs on safety per- }\end{array}$ & 0.009 & 0.266 & Very Weak \\
formance. & & & Weak \\
\hline $\begin{array}{l}\text { Ha 2: There is a significant relationship be- } \\
\text { tween management commitments on safety } \\
\text { performance. }\end{array}$ & 0.002 & 0.313 & Weak \\
$\begin{array}{l}\text { Ha 3: There is a significant relationship be- } \\
\text { tween communication and feedback on safety } \\
\text { performance. }\end{array}$ & 0.000 & 0.375 & Moderate \\
\hline $\begin{array}{l}\text { Ha 4: There is a significant relationship be- } \\
\text { tween employee involvements on safety per- } \\
\text { formance. }\end{array}$ & 0.000 & 0.543 & \\
\hline
\end{tabular}

The results showed the relationships between management practices (training, management commitment, communication and feedback, employee involvement) and safety performance which were used to determine the most effective and significant management practices in the selected company.

Hypothesis Ha 1 supported past study in which Griffin and Neal (2000) stated that personnel training is the important antecedent for safety performance as it is the determinant of employees' knowledge, skill, and motivation (Nahrgang et. al., 2011; Vinodkumar et. al., 2010). The finding also supported by Schlesinger (2017) which found that training perceives as the best practice to reduce the accidents in the workplace. However, the finding showed a very weak relationship between training and safety performance, which implied that training is not a major impact on the safety performance.

The relationship of Hypothesis Ha 1 contradicted a past study from Smith-Crowe, Burke, and Landis (2003). They stated that safety training only acts as a mediating factor between safety knowledge and safety performance. The employees involved in training will utilize the knowledge gained from training if they perceive it is relevant to their work activities (Hatala \& Fleming,

Table 2: Regression analysis of management practices and safety performance

\begin{tabular}{lccccc}
\hline & \multicolumn{2}{c}{$\begin{array}{c}\text { Unstandardized Coeffi- } \\
\text { cients }\end{array}$} & $\begin{array}{c}\text { Standardized Coeffi- } \\
\text { cients }\end{array}$ & $\mathrm{t}$ & Sig. \\
\cline { 2 - 5 } & $\mathrm{B}$ & Std. Error & Beta & & \\
\hline (Constant) & -3.514 & 5.457 & .011 & .103 & .919 \\
Training & .016 & .157 & -.094 & -.725 & .470 \\
$\begin{array}{l}\text { Management Commit- } \\
\text { ment }\end{array}$ & -.138 & .190 & .155 & 1.265 & .209 \\
$\begin{array}{l}\text { Communication and } \\
\text { feedback }\end{array}$ & .259 & .205 & & & .000 \\
Employee Involvement & .642 & .143 & .509 & 4.498 & .000 \\
\hline
\end{tabular}

Notes: $\mathrm{R}^{2}=0.308 ; \mathrm{F}=10.012 ; \mathrm{p}=0.000 ; \mathrm{p}<0.05$ 
2007). Therefore, the result of very weak training impact in this research might be due to ineffective transfer of training in the organization (Smith-Crowe, Burke, and Landis, 2003). In contrast, the finding supported a research done by Taufek, Zulkifle, and Kadir (2016) which indicated that training has a relationship with injury management within the workplace and provides an important impact on the employees' performance in making the workplace safer and healthier.

Hypothesis Ha 2, on the other hand, is supported by past research of Choudhry, Fang and Ahmed (2008) which found that management commitment is one of the determinants to ensure the success of workplace safety performance. The unsafe working condition could be reduced if the managers are aware of and be involved in safety practices. The finding also supported the study by Taufek, et. al. (2016) which showed that management commitment is correlated to the workplace health and safety outcomes. However, the result showed management commitment has a weak impact on safety performance. The could be due to the poor effort of management to effectively motivate or stimulate the workers' interest to be involved in safety practices (Nahrgang, Morgeson \& Hofmann, 2011). Neal and Griffin (2004), on the other hand, contended that management commitment is unremarkable related to the safety outcomes such as the number of injuries or accidents. This might be due to the management is more emphasis the roles of creating safety climate and establishing policy, rules, and procedures without the understanding of the root cause of the problems (Ratnasingam, Ioras, \& Bennet, 2010).
Mearns, Whitaker, and Flin (2003) found that communication is significantly associated with the rate of dangerous occurrence, which communication is an important tool for the workforce in order to understand the workplace health and safety issue. Hypothesis Ha 3 is also supported by Taufek, Zulkifle, and Kadir (2016) claimed that it is crucial to communicate the procedures of improving the process of production with workers whenever an accident happens. Besides, the result also can be explained by the work of Ali, Chew Abdullah and Subramaniam (2009) which stated that regular feedback is vital as it does prevent injury. Therefore, the review of the safety performance acts as a feedback loop for the organization to improve implement a better plan for managing safety performance (Dorji \& Hadikusumo, 2006).

In contrast, a past study from Clarke (2006) reported that job communication was not the intervention as it failed to predict the safety outcomes such as accidents and unsafe behaviour which is contradicted to Hypothesis Ha 3. Communication does not take effect without the commitment of workers because an individual's behaviour is determined by the one who performs the behaviour (Health and Safety Executives, 2002). Based on the result, communication and feedback did not work well in the selected organization as it only has a weak impact on safety performance. Communication can work well if employees are willing to share information and feedback to the top management so that they can understand the needs and problem, while top management willing to listen and take action to solve the issues. 
The present finding in Hypothesis $\mathrm{Ha} 4$ is supported past research from Christian, et. al. (2009) found that safety participation had a direct relationship with safety outcomes such as accidents or injuries occurrence. The results can be explained by the study of Christiansen, Bryan, Chandan and Harish (2017), claimed that employer put excessive job demand on general workers with diversified working requirements, thereby employees require more time to adapt the new skills, and the working hours extend, as well as increased in term of time pressure leading to the stress in the workplace. The pressure is the main cause of the accident happened.

The finding showed that employee involvement has a moderate relationship on safety performance. So, it is important to understand that employee influence has significant impact in determining the safety and healthy working environment (Wachter \& Yorio, 2014). Hence, employees' participation in the safety activities during the work processes could facilitate the safe behaviours and attitude in the workplace, thus increase safety performance and will result in lesser accidents.

In contrast, the finding contradicted past research by Ooshaksaraie and Azadehdel (2015) which found out that employee participation is the weakest component used to determine the safety performance within the workplace. The findings of Clarke (2006) also stated that safety participation was weakly related to the accident incidences. The safety performance is indicated by the initiatives of the employees to involve in the safety program or activities. The result of poor safety performance if employees did not attempt to engage in the safety issues, and vice versa.

\section{CONCLUSION}

In conclusion, researcher found that there is a relationship for the four selected management practices which include training, management commitment, communication and feedback, and employee involvement on the safety performance within the organization. In the meantime, the researcher has found out that the impact of employee involvement within the organization is the most dominant indicator on safety performance. Employee involvement showed a moderate relationship to the safety performance while the rest of management practices were only showed a weak relationship towards the safety performance, which indicated that employee involvement has a high impact on the safety performance such as accidents rates and safety management system. Also, the relationship was supported by some past research explained that management practices could improve workplace health and safety. Management practices is crucial as it is an attempt to remind and guide the stakeholders regarding the safety concerns and issues, and also an effort to prevent the undesired events to happen. Therefore, the organization should invest resources and time into the management practice to manage the safety performance as the safety of the people in the organization is always the top priority.

\section{REFERENCES}

Ali, H., Azimah Chew Abdullah, N., \& Subramaniam, C. (2009). Management practice in safety culture and its influence on workplace injury: An in- 
dustrial study in Malaysia. Disaster Prevention and Management: An International Journal, 18(5), 470-477. doi: 10.1108/09653560911003660

Amponsah-Tawiah, K., \& Mensah, J. (2016). Occupational health and safety and organizational commitment: evidence from the Ghanaian mining industry. Safety and health at work, 7(3), 225-230. Retrieved from https://doi.org/10.1016/j.shaw.2016.0 1.002

Barbera, K. M. (2014). The Oxford handbook of organizational climate and culture. Oxford University Press.

Brown, K. A., Willis, P. G., \& Prussia, G. E. (2000). Predicting safe employee behavior in the steel industry: Development and test of a sociotechnical model. Journal of Operations Management, 18(4), 445-465.

Chai, A. H. (2015). Impacts of selected economics shocks on Malaysian external sector. Retrieved from https://ir.unimas.my/12330/1/Impacts $\% 20$ of $\% 20$ selected $\% 20$ economics $\% 2$ 0shocks\%20on\%20Malaysian\%20ext ernal $\% 20$ sector\%20(24pgs).pdf

Chandrasekar, K. (2011). Workplace environment and its impact on organisationa performance in public sector organisations. International Journal of Enterprise Computing and Business Systems, 1(1), 1-19.

Choudhry, R. M., Fang, D., \& Ahmed, S. M. (2008). Safety management in construction: Best practices in Hong Kong. Journal of professional issues in engineering education and practice, 134(1), 20-32.
Christian, M. S., Bradley, J. C., Wallace, J. C., \& Burke, M. J. (2009). Workplace safety: a meta-analysis of the roles of person and situation factors.

Christiansen, Bryan, Chandan, Harish C. (2017). Handbook of research on organizational culture and diversity in the workplace. IGI Global.

Clarke, S. (2006). Safety climate in an automobile manufacturing plant: The effects of work environment, job communication and safety attitudes on accidents and unsafe behaviour. Personnel Review, 35(4), 413-430.

Clarke, S. (2006). The relationship between safety climate and safety performance: a meta-analytic review.

Department of Occupational Safety and Health. (2017). Archive Statistics 2011-2017: Occupational accidents statistics by sector until December 2011-2017. Retrieved from http://www.dosh.gov.my/index.php/e n/archive-statistics/2017

Department of Occupational Safety and Health. (2017). Occupational diseases and poisoning investigation. Retrieved from http://www.dosh.gov.my/index.php/e n/occupational-diseases-andpoisoning-statistic

DeRoo, L. A., \& Rautiainen, R. H. (2000). A systematic review of farm safety interventions. American journal of preventive medicine, 18(4), 51-62.

Dorji, K., \& Hadikusumo, B. H. (2006). Safety management practices in the Bhutanese construction industry. 
Journal of Construction in Developing Countries, 11(2), 53-75.

Eakin, J. M. (1992). Leaving it up to the workers: sociological perspective on the management of health and safety in small workplaces. International Journal of Health Services, 22(4), 689-704.

Fernández-Muñiz, B., Montes-Peón, J. M., \& Vázquez-Ordás, C. J. (2007). Safety culture: Analysis of the causal relationships between its key dimensions. Journal of safety research, 38(6), 627-641.

Griffin, M. A., \& Neal, A. (2000). Perceptions of safety at work: a framework for linking safety climate to safety performance, knowledge, and motivation. Journal of occupational health psychology, 5(3), 347.

Guldenmund, F. W. (2010). Misunderstanding safety culture and its relationship to safety management. Risk analysis, 30(10), 1466-1480.

Guo, B. H., Yiu, T. W., \& González, V. A. (2016). Predicting safety behavior in the construction industry: Development and test of an integrative model. Safety science, 84, 1-11.

Hatala, J. P., \& Fleming, P. R. (2007). Making transfer climate visible: Utilizing social network analysis to facilitate the transfer of training. Human Resource Development Review, 6(1), 3363.

Health and Safety Executive (HSE), 2002. Strategies to promote safe behaviour as part of a health and safety man- agement system. Contract Research Report 430/2002, UK.

KH Hon, C., Hinze, J., \& PC Chan, A. (2014). Safety climate and injury occurrence of repair, maintenance, minor alteration and addition works: A comparison of workers, supervisors and managers. Facilities, 32(5/6), 188-207.

Krejcie, R. V., \& Morgan, D. W. (1970). Determining sample size for research activities. Educational and psychological measurement, 30(3), 607-610.

Kumar, R., Chelliah, T. D., Chelliah, M. K., \& AMIN, A. F. B. M. (2012). An analysis on safety work culture in Malaysian manufacturing industry. BIOINFO Business Management, 2(1), 11-15.

Leigh, J. (2011). Economic burden of occupational injury and illness in the United States. The Milbank Quarterly, 89(4), 728-772.

Makin, A. M., \& Winder, C. (2008). A new conceptual framework to improve the application of occupational health and safety management systems. Safety Science, 46(6), 935-948.

Mashi, M. S., Subramaniam, C., \& Johari, J. (2018). The effect of management commitment to safety, and safety communication and feedback on safety behavior of nurses: the moderating role of consideration of future safety consequences. The International Journal of Human Resource Management, 1-30.

Mearns, K., Whitaker, S. M., \& Flin, R. (2003). Safety climate, safety man- 
agement practice and safety performance in offshore environments. Safety science, 41(8), 641-680.

Mukaka, M. M. (2012). A guide to appropriate use of correlation coefficient in medical research. Malawi Medical Journal, 24(3), 69-71.

Nahrgang, J. D., Morgeson, F. P., \& Hofmann, D. A. (2011). Safety at work: a meta-analytic investigation of the link between job demands, job resources, burnout, engagement, and safety outcomes. Journal of Applied Psychology, 96(1), 71.

Ng, A. (2017). Work in Malaysia: An uneven future? Retrieved from https://themalaysianreserve.com/2017 /10/17/work-malaysia-uneven-future/

Nordlöf, H., Wiitavaara, B., Högberg, H., \& Westerling, R. (2017). A Crosssectional study of factors influencing occupational health and safety management practices in companies. Safety science, 95, 92-103.

Omotayo, A. O., \& Adenike, A. A. (2013). Impact of organizational culture on human resource practices: a study of selected Nigerian private universities. Journal of Competitiveness, 5(4).

Ooshaksaraie, M., \& Azadehdel, M. R. (2015). An Empirical Study of Safety Performance Assessment. International Journal of Occupational Hygiene, 6(4), 201-209.

Probst, T. M., \& Estrada, A. X. (2010). Accident under-reporting among employees: Testing the moderating influence of psychological safety climate and supervisor enforcement of safety practices. Accident Analysis \& Prevention, 42(5), 1438-1444.

Ratnasingam, J., Ioras, F., \& Bennet, M. (2010). Determinants of workers health and safety in the Malaysian wooden furniture industry. Journal of Applied Sciences, 10(5), 425-430.

Reason, J. (2000). Human error: models and management. BMJ: British MedicaL Journal, 320(7237), 768.

Reason, J. T. (1997). Managing the risks of organisational accidents. Aldershot: Ashgate.

Said, S. M., Halim, Z. A., \& Said, F. (2012). Workplace injuries in Malaysian manufacturing industries. Journal of Occupational Safety and Health, 21.

Sawhney, G., Cigularov, K. P., Chen, P., Dejoy, D., Huang, Y. H. E., Kelloway, E. K., \& Scharf, T. (2011). Safety climate theory, measurement, and development: Establishing a fiveyear research agenda.

Schlesinger, D. (2017). FRA Training requirements. In 2017 Joint Rail Conference (pp. V001T06A002 V001T06A008). American Society of Mechanical Engineers. Retrieved from

http://proceedings.asmedigitalcollecti on.asme.org/proceeding.aspx?articlei $\mathrm{d}=645420$

Schlesinger, D. (2017). Organizational culture. In 2017 Joint Rail Conference (pp. V001T06A008-V001T06A015). American Society of Mechanical Engineers. Retrieved from http://proceedings.asmedigitalcollecti 
on.asme.org/proceeding.aspx?articlei $\mathrm{d}=2645426$

Smith-Crowe, K., Burke, M. J., \& Landis, R. S. (2003). Organizational climate as a moderator of safety knowledgesafety performance relationships. Journal of Organizational Behavior, 24(7), 861-876.

Sørensen, O. H., Hasle, P., \& Bach, E. (2007). Working in small enterprisesis there a special risk? Safety Science, 45(10), 1044-1059.

Taufek, F. H. B. M., Zulkifle, Z. B., \& Kadir, S. Z. B. A. (2016). Safety and health practices and injury management in manufacturing industry. Procedia economics and finance, 35, 705-712.

Toft, Y., Dell, G., Klockner, K., \& Hutton, A. (2012). Models of causation safety. Retrieved from http://acquire.cqu.edu.au:8080/vital/a ccess/manager/Repository/cqu:11582

Trading Economics. (2017). Malaysia GDP from manufacturing 2010-2017. Retrieved from https://tradingeconomics.com/malaysi a/gdp-from-manufacturing Unnikrishnan, S., Iqbal, R., Singh, A., \& Nimkar, I. M. (2015). Safety management practices in small and medi um enterprises in India. Safety and health at work, 6(1), 46-55.

Vinodkumar, M. N., \& Bhasi, M. (2010). Safety management practices and safety behaviour: Assessing the mediating role of safety knowledge and motivation. Accident Analysis \& Prevention, 42(6), 2082-2093.

Wachter, J. K., \& Yorio, P. L. (2014). A system of safety management practices and worker engagement for reducing and preventing accidents: An empirical and theoretical investigation. Accident Analysis \& Prevention, 68, 117-130. Retrieved from http://www.sciencedirect.com/science /article/pii/S0001457513002972

Watson, G. W., Scott, D., Bishop, J., \& Turnbeaugh, T. (2005). Dimensions of interpersonal relationships and safety in the steel industry. Journal of Business and Psychology, 19(3), 303318.

Zakaria, Z., Hussin, Z. H., Noordin, N., \& Zakaria, Z. (2010). Accidents at the construction site in northern area: Malaysian experienced. Management Science and Engineering, 4(3), 106116. 